Perfis de mestres 


\section{Fernando de Azevedo}

\section{NELSON PIEETTI}

$\mathrm{N}$ o início dos anos 70, recém-chegado a São Paulo, forçado a deixar o Rio Grande por razóes políticas - demitido que fôra pelas escolas em que lecionava e pelo Banco do Brasil - andava à procura de um tema para a minha dissertação de mestrado quando me deparei com uma notícia de jornal: Fernando de Azevedo doara o seu arquivo pessoal ao Instituto de Estudos Brasileiros. Era o fim do meu problema, o início de intermitentes e profícuos mergulhos na obra do insigne educador e sociblogo, dos quais invariavelmente emergia com o espírito revitalizado por novas e instigantes descobertas.

Desde então, por mais que tivesse tentado, orientando minhas investigaçóes para outros temas, nunca mais consegui me libertar de sua presença, fascinado por sua controversa figura ou premido pelas circunstâncias. A partir da dissertaçáo de mestrado, restrita ao estudo da reforma educacional por ele promovida no Distrito Federal, entre 1927 e 1930 - marco fundamental entre as inúmeras tentativas de renovação do nosso ensino - ampliei a abrangência das minhas pesquisas, na tentativa de compreender a sua trajetória intelectual e humana, que procurei tornar conhecida no trabalho Fermando de Azevedo: a educafáo como desafio, elaborado para o INEP em 1984, décimo aniversário de sua morte, e em vários artigos publicados em 1994, ano do centenário do seu nascimento.

Hoje, tomado de perplexidade ante a situaçáo nacional, em particular no campo educacional, em todos os seus níveis e modalidades, volto a Fernando de Azevedo, quiçá em busca de alguma luz que ilumine nossos caminhos, e me pergunto: com base em minhas limitadas investigaçóes e reflexóes, que perfil poderia traçar de Fernando de Azevedo? Quem foi o homem Fernando de Azevedo?

Fernando de Azevedo foi um bomem extremamente organizado e meticuloso. Foi a primeira impressão que tive, ao entrar em contato com o seu arquivo e folhear os dez grossos volumes contendo recortes de jornais, aproximadamente sete mil matérias sobre a sua administração à frente da Diretoria de Instruçáo Pública do Distrito Federal. E todos caprichosamente organizados em ordem cronológica, identificados pelo nome do jornal e pela data de publicação, escritos de próprio punho por Fernando de Azevedo. 
Fernando de Azevedo foi um bomem obcecado pelo trabalbo. E aqui recorro ao testemunho de sua filha Lollia, para quem o pai foi um trabalhador incansável, um batalhador: quando chegava em casa, depois de falar conosco e nos beijar, afastávamo-nos indo brincar onde năo nos ouvisse. 'Seu pai precisa trabalhar', como minha mãe dizia, sempre vigilante para que ele tivesse a paz necessária". E mais: "Escreveu até o fim da vida. Conseguia escrever mesmo sem enxergar, depois eu lia o que ele havia escrito, corrigia ou modificava se assim ele achasse necessário".

Fernando de Azevedo foi um bomem obstinado, que, ainda de acordo com Lollia, "até o fim trabalhou e lutou pelos seus ideais". Ou, no dizer de Antonio Cândido, "um exemplar raro de homem que gostava da responsabilidade e cuja lucidez é aguçada, não embotada, pelas dificuldades, porque elas espicaçam o seu ânimo combativon. Sua obstinaçáo ficou evidente, por exemplo, na reforma educacional que promoveu no Distrito Federal, quando lutou tenazmente para modernizar o sistema de ensino, enfrentando poderosos interesses fincados no Conselho Municipal, a famosa gaiola de ouro, quando chegou a sofrer um atentado. No calor dos debates, diante da intransigência dos intendentes situacionistas, que relutavam em apoiar a reforma, emitiu uma explosiva nota afirmando a certa altura: "O Diretor de Instruçáo elaborou um projeto de lei e o ofereceu ao Conselho Municipal, atendendo a um convite com que o honraram as comissóes reunidas de Instrução, Justiça e Orçamento. Se nada vale, deve ser rejeitado; se tem defeitos, deve ser emendado; se é obra digna de apreço, deve ser aprovada. Supor o Diretor de Instrução Pública capaz de ceder a qualquer pressão ou transação é desconhecế-lo, senão injuriá-lon. Os princípios da reforma escola única, náo uniforme, mas adaptada ao meio; escola do trabalho, ao mesmo tempo conteúdo curricular e método pedagógico; e escolacomunidade ou escola do trabalho em cooperação - continuam, em nossa realidade educacional, ideais em busca de realizaçăo.

Fernando de Azevedo foi um homem de pensamento, com múltiplos interesses intelectuais, para quem nada do que é bumano era estranbo. Da educaçáo física - área em que foi especialista, tendo escrito uma tese pioneira em 1915 - às ciências sociais, trajetória que completou em 20 anos, transitou pelo ensino de latim e de psicologia, pela crítica literária, pela investigaçăo sobre a arquitetura colonial e sobre a educaçáo paulista, pela reforma educacional. Estudioso e amante dos clássicos, nunca escondeu o seu fascínio pelas ciências modernas, que procurou incluir nos currículos escolares, tanto que, nos anos 50, organizou a obra As ciencias no Brasil, cuja segunda edição acaba de sair pela Universidade Federal do Rio de Janeiro em 1994. Entre 25 livros, a maioria 
na área da educação, escreveu obras pioneira no campo das ciências sociais como Princípios de Sociologia (1935), Sociologia Educacional (1940) e Canaviais e engenhos na vida politica do Brasil (1948).

Segundo o testemunho insuspeito de Paschoal Lemme, Fernando de Azevedo foi "uma das mais altas expressóes da inteligência e da cultura do Brasil moderno", destacando-se por três contribuiçōes fundamentais: "1. A grande reforma do ensino no antigo Distrito Federal (1927-1930) (...), reforma essa que, segundo as opiniōes mais autorizadas, foi o marco inicial do processo de modernizaçăo do ensino no

Fernando de Azevedo

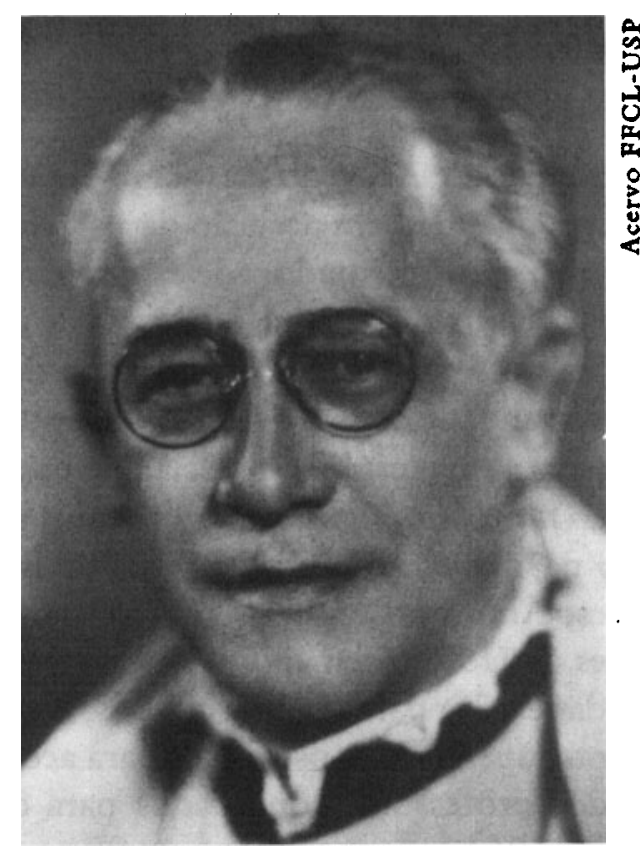

Brasil. 2. O Manifesto dos pioneiros da educafáo nopa (1932) (...), documento único na história da educação brasileira. (...) Subscrito por um grupo dos mais eminentes educadores e intelectuais, mantém até hoje sua validade. 3. A monumental obra $A$ cultura brasileira, redigida inicialmente para servir de introduçáo ao recenseamento de 1940 , tornou-se de consulta obrigatória para quem deseja conhecer a evolução da cultura nacional, em todos os seus aspectos" (Carta ao Jornal do Brasil, 1976). A estas três poderíamos acrescentar uma quarta contribuição, que foi a sua importante participação no processo de fundação da Universidade de São Paulo (1934), destacando-se como um lutador incansável pela implementação do verdadeiro espirito unipersitário, plena- 
mente identificado com a Faculdade de Filosofia, Ciências e Letras como anima mator da Universidade.

Fernando de Azevedo foi um bomem de afaro, tendo exercido vários cargos administrativos, a maioria na esfera educacional, entre os quais podem ser destacados: diretor-geral da Instruçáo Pública do Distrito Federal (1927-1930); diretor-geral da Instruçáo Pública do Estado de São Paulo (1933); diretor do Instituto de Educaçăo da Universidade de São Paulo (1933-1938); diretor da Faculdade de Filosofia, Ciências e Letras da USP (1941-1943); chefe do Departamento de Sociologia e Antropologia da FFCL da USP (1947); secretário de Educaçáo e Saúde do Estado de São Paulo (1947); diretor do Centro Regional de Pesquisas Educacionais de São Paulo (1956-1960); secretário de Educaçáo e Cultura do Munićpio de Sáo Paulo (1961).

Fernando de Azevedo foi, acima de tudo, um bomem trategro, um bumanista na verdadeira acepçăo da palavra. Por isso, um homem permanentemente atormentado, "de espírito inquieto e insatisfeito consigo mesmo e com quase tudo que vê à volta de si", como reconheceu em seu discurso de posse na Academia Brasileira de Letras, em 1968. Por isso, um homem que lutou pelo desenvolvimento do humanismo, o qual, $\mathrm{em}$ suas palavras, "não está na matéria que ensinamos (seja qual for, letras ou ciências), mas no esptrito que nos anima no ensino de qualquer disciplina e na maneira de ensiná-lan. Por isso, que o digam Florestan Fernandes, Antonio Cândido e Maria Isaura Pereira de Queiroz, seus assistentes na USP, o seu apoio àqueles que com ele trabalharam, a sua solidariedade ativa para com os colegas, levando-o a comparecer espontaneamente, apesar de aposentado, para acompanhar de perto os depoimentos dos professores convocados para depor em inquérito policial militar, em 1964.

Finalizo com Antonio Cândido, sem dúvida a melhor companhia neste caso: "Como seu aluno e em seguida seu colaborador de muitos anos; como seu discípulo e amigo, quero que este testemunho sirva principalmente para transmitir ds geraçōes novas a lembrança de um homem insigne, que possuía a retidáo escarpada dos lutadores e a ternura afetuosa dos grandes coraçóes".

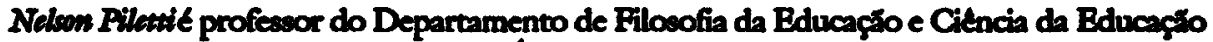
da Faculdade de Educacăo da USP. E autor de A Reforma Fermundo de Azereato - DR, 1927-30 (FE-USP, Coleçá Botudos e Documentos n? 20, 1982) e Fermando do Aremedo: a aturapfio como desugio (Instinuto Nacional de Betudos e Pesquisas Educacionais, INEP-MEC, Brastia, 1985). 